\title{
Prevalence and Socio-Demographic/ Economic Risk Factors of Low and High Body Mass Index of Urban versus Rural Pregnant Women at Booking for Antenatal Care in Governmental Health Centers of Jimma Zone, Southwest Ethiopia
}

\author{
Chernet Hailu ${ }^{*}$, Tariku Dejene ${ }^{2}$, Bosena Tebeje ${ }^{3}$ \\ ${ }^{1}$ Epidemiology Department, College of Public Health and Medical Sciences, Jimma University, Jimma, Ethiopia \\ ${ }^{2}$ College of Development Studies, Addis Ababa University, Addis Ababa, Ethiopia \\ ${ }^{3}$ Nursing Department, College of Public Health and Medical Sciences, Jimma University, Jimma, Ethiopia \\ Email: ${ }^{*}$ chernet mengesha@yahoo.com, tariku_dejene@yahoo.com, bosenatebeje@yahoo.co.uk
}

Received 21 June 2015; accepted 5 July 2015; published 13 July 2015

Copyright (C) 2015 by authors and OALib.

This work is licensed under the Creative Commons Attribution International License (CC BY).

http://creativecommons.org/licenses/by/4.0/

(c) (i) Open Access

\section{Abstract}

Background: Low Body Mass Index (BMI) continues to be a major health burden in addition to the emergence of new competing public health priority (high BMI) in developing countries. Abnormal BMI threatens both the health and survival of mothers and their infants, because it increases their susceptibility to life-threatening problems during pregnancy, and during and following childbirth. Although a number of studies done on nutrition, none was done in pregnancy in our country including Jimma Zone. Objective: The aim of this study was to assess prevalence and identify the risk factors associated with BMI status of pregnant women of urban versus rural residents of Jimma Zone, Southwest Ethiopia. Methods: A cross-sectional study was conducted from March 03 to October 21, 2011 in randomly selected governmental health centers of Jimma Zone. A total of 1546 pregnant mothers (770 urban and 776 rural residents) who fulfilled the inclusion criteria were included in the study. Structured interviewer administered questionnaires were used for data collection: first exploratory/descriptive data analysis, then, multinomial logistic regression analysis employed using SPSS version 16.0 and significance level of 0.05 . Results: Majority of, $60.8 \%$ urban and $60.2 \%$ rural resident, pregnant mothers had normal BMI at the time of their first booking for Antenatal Care (ANC) on static/outreach basis in the selected governmental health centers or Woredas (districts) of the Zone. Prevalence of low BMI (BMI $\leq 20 \mathrm{~kg} / \mathrm{m}^{2}$ ) was higher in rural $(27.3 \%)$ than urban $(22.3 \%)$ pregnant mothers, whereas high BMI $\left(B M I>24 \mathrm{~kg} / \mathrm{m}^{2}\right)$ was higher in

\footnotetext{
"Corresponding author.

How to cite this paper: Hailu, C., Dejene, T. and Tebeje, B. (2015) Prevalence and Socio-Demographic/Economic Risk Factors of Low and High Body Mass Index of Urban versus Rural Pregnant Women at Booking for Antenatal Care in Governmental Health Centers of Jimma Zone, Southwest Ethiopia. Open Access Library Journal, 2: e1672.

http://dx.doi.org/10.4236/oalib.1101672
} 
the urban $(16.9 \%)$ than rural $(12.6 \%)$ pregnant mothers $(p<0.05)$. The Woredas decreasing order by proportion of low BMI mothers was Kersa (37.6\%), Omonada (33.3\%) and Mana (28.5\%) Gera (19.2\%), Shebe Sombo (17.4\%) and Seka Chekorsa (12.5\%); whereas, the order by proportion of high BMI mothers was Gera (23.5\%), Omonada (22.1\%), Shebe Sombo (14.7\%), Seka Chekorsa $(10.2 \%)$, Mana $(9.4 \%)$ and Kersa $(8.5 \%)(P<0.001)$. After employing multivariate multinomial logistic regression analysis: the important factors found independently associated with high BMI of the urban pregnant mothers were primary and above education level (AOR $=2.13,95 \%$ CI, 1.21 - 3.74) and $3^{\text {rd }}$ trimester gestation period (AOR $=3.21,95 \% \mathrm{CI}, 2.02-5.9$ ). While, higher monthly household expenditure (351 - 500 Eth.birr, AOR = 1.89, 95\% CI, $1.21-2.95 ; 501-700$ Eth.birr, AOR = 2.80, 95\% CI, 1.67 - 4.72; 701 - 1000 Eth.birr, $\mathrm{AOR}=2.07,95 \% \mathrm{CI}, 1.07$ - 4.02) and $3^{\text {rd }}$ trimester gestation period $(A O R=0.44,95 \% \mathrm{CI}, 0.29-0.69)$ were for low BMI of the rural pregnant mothers at the time of their booking for ANC. Conclusion: A considerable proportion of both urban and rural pregnant mothers had low BMI as well as high BMI (higher in urban than rural). Therefore, strengthening antenatal care on nutrition, introducing/enhancing the culture of nutritional (BMI) status determination and monitoring starting $1^{\text {st }}$ trimester of pregnancy, preferably in pre-pregnancy period of reproductive age women, and undertaking further studies on the issue in different settings of the country are advisable.

\section{Keywords}

Underweight, Overweight/Obesity, BMI, Pregnant Mothers, ANC Booking, Ethiopia

Subject Areas: Nutrition

\section{Introduction}

Women in the reproductive age group and children are most vulnerable to malnutrition due to low dietary intakes, inequitable distribution of food within the household, improper food storage and preparation, dietary taboos, infectious diseases, and care [1]. Under nutrition threatens both the health and survival of mothers and their infants, because it increases their susceptibility to life-threatening diseases and their risk of dying, especially during childbirth [2]. Gaining too much weight and obesity is also associated with an increased risk of medical and puerperal complications, including hypertension, preeclampsia, gestational diabetes mellitus, thrombophlebitis, labor abnormalities including prolonged second-stage labor, delivery after 42 weeks of gestation, and cesarean delivery. Operative complications among obese women undergoing cesarean delivery include increased blood loss, prolonged operative time, and increased rates of postoperative infection [3]. Excessive weight gain may also cause problems for the baby. Large babies make vaginal deliveries difficult, increasing the risk for cesarean section. Overweight babies may have an increased risk for health problems later in life (e.g., obesity, diabetes, and cardiovascular problems) [4].

Worldwide, estimated 852 million people are undernourished with most (815 million) living in developing countries [5] [6]. Poverty is the main underlying cause of malnutrition and its determinants [7]. The degree and distribution of Protein Energy Malnutrition (PEM) in a given population depend on many factors - the socioeconomic situation, level of education and sanitation, the season and climate conditions, food production, cultural and religious food customs, breastfeeding habits, prevalence of infectious diseases, the existence and effectiveness of nutrition programs and the availability and quality of health services [6] [8].

Under-nutrition or low Body Mass Index (BMI) continues to be a major health burden in addition to the emergence of new competing public health priority (high BMI) in developing countries [9]. It is globally the most important risk factor for illness and death with hundreds of millions of pregnant women and young children particularly affected [10]. Poor nutrition in pregnancy in combination with infections is a common cause of maternal and infant mortality and morbidity, low birth weight and Intrauterine Growth Retardation (IUGR) [11].

Ethiopia is the second most populous country in Africa, and is a home to about 74 million people, most of who live in rural areas [12]. According to the study by the Ethiopian Ministry of Economic Development and 
Cooperation, 50 percent of the Ethiopian population are living below the food poverty line and cannot meet their daily minimum nutritional requirement of 2200 calories [13]. The country's maternal health statistics are grim: the number of maternal deaths is fifth highest in the world [14] and the maternal mortality ratio, estimated to be 673 per 100,000 live births, is extremely high [15]. The extent to which malnutrition contributes to these maternal deaths is unknown. However, it remains one of the world's highest priority health issues not only because its effects are so widespread and long lasting but also because it can be eradicated [14].

Researches have been done in the countries where pre-pregnant BMI determination is difficult; $1^{\text {st }}$ visit pregnancy BMI has been used to determine the nutritional status of the mothers and assess pregnancy BMI risk factors (like age, parity, economic status). In most developing countries including Ethiopia women do not tell their baseline weight and height; in this situation the need to determine weight and height and thereby pregnancy BMI at $1^{\text {st }}$ Antenatal Care (ANC) booking becomes evident so as to guide the counseling need on nutrition during subsequent ANC visits [10] [16]-[21]. Additionally, adverse outcomes of abnormal pregnancy BMI such as pre-eclampsia, induced labor, postpartum hemorrhage, preterm delivery, birth weights less than $2500 \mathrm{~g}$ and birth weights $>4000$ g were documented in other researches [22].

However, such study was not carried out in Ethiopia. The authors believe that, in order to reduce (prevent) the adverse outcomes of abnormal pregnancy BMI, the need to identify groups of pregnant women at greater risk of developing abnormal BMI and identify its modifiable risk factors would have paramount importance. Therefore, this study was proposed to determine and compare prevalence and identify important independent socio-demographic/economic risk factors of low and high BMI among urban versus rural pregnant women at their first visit or booking for ANC in governmental health centers of Jimma Zone, Southwest Ethiopia.

\section{Methods}

\subsection{Study Area and Period}

Jimma zone is bordered on the south by the Southern Nations, Nationalities and Peoples Region, on the northwest by Illubabor zone, on the north by East Wollega, and on the northeast by South Shoa. According to the 2007 census, Jimma zone is consisted of 17 Woredas (districts) with a total population of 2,495,795 (141,013 in urban and 2,354,782 in rural areas) [12]. Currently each Woreda has at least one governmental health center. The study was conducted from March 03-October 21, 2011.

\subsection{Study Design}

A health facility based cross-sectional study design was used to assess the prevalence and identify risk factors of different categories of BMI of pregnant women of urban versus rural residents.

\subsection{Population}

Target population: All pregnant women residing in Jimma zone and visiting governmental health centers of the zone.

Study population: All pregnant women residing in Jimma zone and who were visiting governmental health centers of the zone during the study period.

\subsection{Sample Size and Sampling Technique}

To estimate the difference in proportion of underweight for the two groups of the population, the number of samples required (using equal allocation, $n=n_{1}=n_{2}$ ), for each group, was computed as follows:

$$
n=\frac{\left[Z_{\alpha / 2} \sqrt{P_{1}(1-P)_{1}+P_{2}\left(1-P_{2}\right)}\right]^{2}}{d^{2}}
$$

where, $P_{1} \& P_{2}$ are prevalence of underweight in the two populations, pregnant women residing in urban and rural areas of Jimma zone, respectively, and the degree of precision is represented by $d$. With an assumption of $\mathrm{d}$ $=0.05, \alpha=0.05$, and $P_{1}=P_{2}=0.5$ (since there was no published report for the prevalence of underweight among pregnant women at their first visit (booking) for ANC in health centers, for the study area), the minimum sample size required for the study was 1538, that was, 769 subjects from each population. 
Study units were selected using a two stage sampling technique. First, 6 out of the 17 Woredas were selected using simple random sampling technique. From each selected Woreda one health center was selected randomly. Then, all pregnant women who were eligible for the study and visiting the health institution during the study period were included in the study until an allocated number (129 for urban and 129 for rural residents ) for each institution was filled as depicted in Figure 1.

Inclusion and exclusion criteria: Those pregnant mothers who have been residing for at least 6 months in the zone, conscious, able to communicate verbally during their current visit and had a documented data on weight, height and health condition during the date of their first visit or booking for ANC were included in the study. Those who did not fulfill these inclusion criteria were not included in the study.

\subsection{Study Variables}

Outcome variable: BMI of pregnant women (low, normal, high).

Explanatory variables: Socioeconomic and demographic characteristics of the respondents.

Possible confounding variables: Gestational period and health problem during booking for ANC.

\subsection{Operational Definitions}

Body mass index (BMI) is defined as $\frac{\text { weight }(\mathrm{kg})}{[\text { height }(\mathrm{m})]^{2}}$ and classified [23] as:

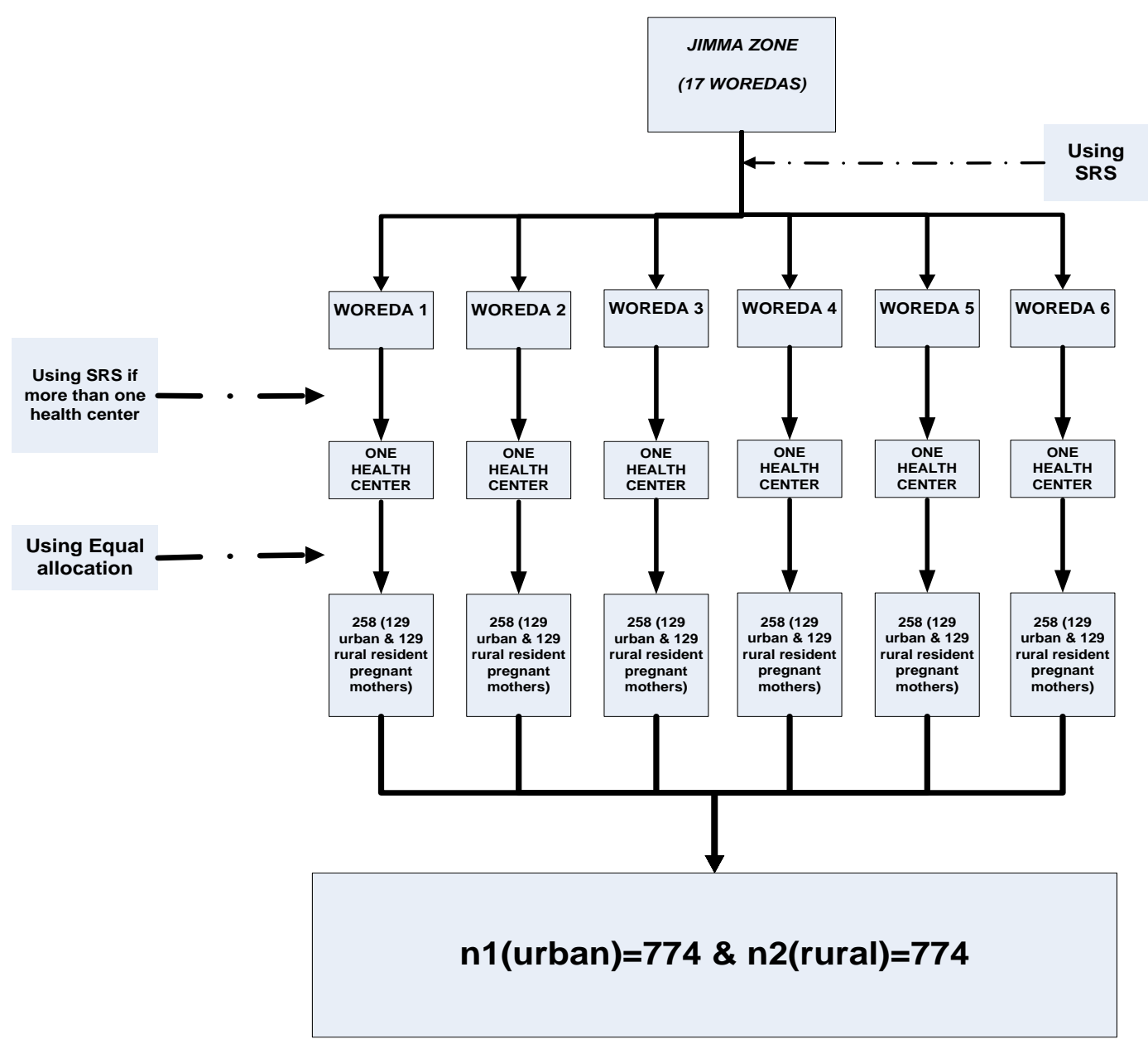

Figure 1. Schematic presentation of sampling procedure. NB: the 258 subjects allocated per each health center is due to rounding up of decimals. 
Low BMI (under weight): Those pregnant mothers with a BMI $\leq 20 \mathrm{~kg} / \mathrm{m}^{2}$.

Normal BMI (normal weight: Those pregnant mothers with $20 \mathrm{~kg} / \mathrm{m}^{2}<\mathrm{BMI} \leq 24 \mathrm{~kg} / \mathrm{m}^{2}$.

High BMI (over weight and obesity): Those pregnant mothers with a BMI $>24 \mathrm{~kg} / \mathrm{m}^{2}$.

Urban residents: Mothers residing in Kebeles considered as urban by the 2007 census report of Ethiopia (Oromiya Region) [24]. Otherwise, they were considered as rural residents.

Data collection instrument: A pre-tested structured questionnaire was used to collect the socio-demographic and economic characteristics of the pregnant mothers. On the other hand, ANC card review was made to obtain information on health problem, gestation weeks, weight and height measurements of the mother at first ANC Visit. The gestation weeks at booking found in the ANC cards of the mothers were determined by the antenatal care providing health workers of the health facilities mainly based on their assessment of fundal height of the mothers at booking, since most of the mothers do not recall and report the exact date of their last menstrual period (LMP) at booking time.

Data collection procedure: Data collection was carried out from March 03-Oct 21, 2011 with six nurses/ midwifes speaking both Oromifa and Amharic languages, and working in the antenatal care units of the selected health centers. To enable identification of mothers of urban and rural residents, the list of urban and rural Kebles of the zone (on the basis of the 2007 census) was given to the data collectors [24]. The 3 principal investigators conducted one day training for these data collectors on how to carry out the data collection using questionnaires prepared for the study.

Pre-test: The instrument of data collection was tested (1 day at the six different data collection sites) a week before the actual study in another similar population (5\% of the sample size). The data was not included in the analysis of the actual study. Necessary modifications were made on the instrument based on the result of the pretest.

Data quality control measures: The questionnaire was prepared based on available literatures and maximum effort was made to include or adopt standard questions (relevant to the study variables), which have been used by previous researchers [15]. The questionnaire were translated into both Amharic and Oromifa language and checked. Moreover, in addition to giving training to research assistants and the questionnaire was pre-tested and necessary correction measures were made after the pretest. During the actual data collection, principal investigators supervised the data collection process, and checked the consistency and completeness of 5 - 10 samples of the completed questionnaires on weekly basis. The data was entered and cleaned carefully before the commencement of the analysis by the investigators of the study.

Data processing and analysis: All data from the field questionnaires were edited and entered in to Epi data version 3.1. The data were exported to SPSS version 16.0 for cleaning, recoding and analysis. Exploratory and descriptive data analysis were employed for the key variables to describe the characteristics of the studied pregnant mothers. Cross-tabulations and chi-square-test were used to describe the proportions and examine for the presence of statistically significant difference in the frequencies of the BMI categories by health centers (Woredas)/residence (urban Vs rural) and sociodemographic/economic variables of the respondents. Then, multinomial logistic regression analysis was employed using enter method to control potential confounding effect of gestation period, health problem and the other explanatory variables in order to identify important independently associated factors for low BMI and high BMI of the studied urban and rural pregnant women separately. A significance level of 0.05 was used to decide the significance of statistical tests.

Ethical considerations: Ethical approval was secured from Ethical Review Board of Jimma University. Permission was sought from authorities of Jimma Zone health office, the study Woredas/health institutions and also informed consent to participate in the study was obtained from each study participant before data collection undertaken by the data collectors. The information sheet, consent and questionnaire was translated into local language. Name of the respondents was not recorded on the questionnaire to ensure the confidentiality and anonymity of the information. The respondents were assured that their right to refuse participating would be respected and would not affect their care in any way. Besides, the published research report will be disseminated to all concerned agencies/bodies in order to benefit the study and target population at large.

\section{Results}

A total of 1546 pregnant mothers (770 urban and 776 rural residents) who fulfilled the inclusion criteria were included in the study. The response rate varies for different variables of the study ranging between $93.9 \%$ for 
household expenditure and $100 \%$ for most of the variables like gestation period, autonomy, health problem at booking, season at booking, and for the composite variable BMI (dependent variable of the study).

\subsection{Socio-Demographic Characteristics}

The mean age of the respondent pregnant mothers was 24 years $(\mathrm{SD}=5.08)$ and ranges from 15 to 45 years. Majority (46.2\%) of them, 331 (43.2\%) of urban and 382 (49.2\%) of rural respondents, were in the age group of 25 years and above. Three hundred and fifteen (41.7\%) of urban and 611 (79.7\%) of rural with a total of 926 (60.8\%) of respondents were illiterate. Six hundred eighty one (45.0\%) of the pregnant mothers, 377 (49.7\%) of urban and $304(40.2 \%)$ rural residents, were nullipara. The studied pregnant mothers' mean gestation week was 21.8 weeks $(S D=6.97)$. More than half $(59.7 \%)$ of them, $468(60.8 \%)$ urban and $455(58.6 \%)$ rural residents, were in the second trimester pregnancy (13 - 24 weeks of gestation) (Table 1).

Table 1. Socio-demographic/economic characteristics of respondent pregnant mothers in governmental health centers of Jimma Zone, Southwest Ethiopia, March-October 2011.

\begin{tabular}{|c|c|c|c|}
\hline \multirow{3}{*}{ Characteristics } & \multicolumn{2}{|c|}{ Place of Residence } & \multirow[b]{2}{*}{ Total } \\
\hline & Urban & Rural & \\
\hline & $\mathrm{N}(\%)$ & $\mathrm{N}(\%)$ & N (\%) \\
\hline \multicolumn{4}{|l|}{ Age (years) } \\
\hline $15-19$ & $142(18.5)$ & $115(14.8)$ & $257(16.7)$ \\
\hline $20-24$ & 293 (38.3) & $279(36.0)$ & $572(37.1)$ \\
\hline $25+$ & 331 (43.2) & $382(49.2)$ & $713(46.2)$ \\
\hline Total & $766(100.0)$ & $776(100.0)$ & $1542(100.0)$ \\
\hline \multicolumn{4}{|l|}{ Education } \\
\hline Illiterate & 315 (41.7) & $611(79.7)$ & $926(60.8)$ \\
\hline Read and Write & $263(34.8)$ & $68(8.9)$ & 331 (21.7) \\
\hline Primary and above & $178(23.5)$ & $88(11.5)$ & $266(17.5)$ \\
\hline Total & $756(100.0)$ & $767(100.0)$ & $1523(100.0)$ \\
\hline \multicolumn{4}{|l|}{ Parity } \\
\hline Nullipara & 377 (49.7) & $304(40.2)$ & $681(45.0)$ \\
\hline Primipara & $136(17.9)$ & $116(15.3)$ & $252(16.6)$ \\
\hline Multipara & $245(32.3)$ & $337(44.5)$ & $582(38.4)$ \\
\hline Total & $758(100.0)$ & $757(100.0)$ & $1515(100.0)$ \\
\hline \multicolumn{4}{|l|}{ Gestation weeks (period) } \\
\hline $1^{\text {st }}$ Trimester & $67(8.7)$ & $79(10.2)$ & $146(9.4)$ \\
\hline $2^{\text {nd }}$ Trimester & $468(60.8)$ & 455 (58.6) & $923(59.7)$ \\
\hline $3^{\text {rd }}$ Trimester & $235(30.5)$ & $242(31.2)$ & 477 (30.9) \\
\hline Total & $770(100.0)$ & $776(100.0)$ & $1546(100.0)$ \\
\hline \multicolumn{4}{|l|}{ Autonomy } \\
\hline No & $275(35.7)$ & $462(59.5)$ & $737(47.7)$ \\
\hline Yes & $495(64.3)$ & $314(40.5)$ & 809 (52.3) \\
\hline Total & $770(100.0)$ & $776(100.0)$ & 1546 (100.0) \\
\hline
\end{tabular}




\section{Continued}

Monthly household expenditure

$$
\begin{gathered}
\leq 350 \text { Eth.birr } \\
351 \text { - } 500 \text { Eth. birr } \\
501 \text { - } 700 \text { Eth.birr } \\
>700 \text { Eth.birr }
\end{gathered}
$$$$
\text { Total }
$$

Solid waste disposal system

Unsafe
Safe
Total

Safety of drinking water

Yes
No
Total

Latrine facility

Open field/pit system

Covered pit/water carriage system

$$
\text { Total }
$$

Health problems at booking

Yes
No
Total

Season at booking

$\begin{array}{cc}\text { Tseday } & 78(10.1) \\ \text { Bega } & 124(16.1) \\ \text { Belg } & 348(45.2) \\ \text { Kiremt } & 220(28.6) \\ \text { Total } & 770(100.0)\end{array}$

$$
\begin{aligned}
& 108(14.7) \\
& 229(31.1) \\
& 231(31.3) \\
& 169(22.9) \\
& 737(100.0)
\end{aligned}
$$

$770(100.0)$

138 (17.9)

632 (82.1)

770 (100.0)

389 (50.5)

381 (49.5)

770 (100.0)

152 (19.7)

618 (80.3)

770 (100.0)
284 (39.8)

392 (27.0)

225 (31.5)

454 (31.3)

131 (18.3)

362 (24.9)

74 (10.4)

243 (16.7)

714 (100.0)

$1451(100.0)$

505 (32.7)

1040 (67.3)

1545 (100.0)

775 (100.0)

105 (13.6)

243 (15.7)

669 (86.4)

1301 (84.3)

774 (100.0)

$1544(100.0)$

821 (53.2)

432 (55.9)

722 (46.8)

341 (44.1)

1543 (100.0)

773 (100.0)

311 (20.1)

159 (20.5)

1235 (79.9)

617 (79.5)

1546 (100.0)

776 (100.0)

108 (7.0)

306 (19.8)

807 (52.2)

325 (21.0)

1546 (100.0)

Monthly household expenditure categories made based on its quartiles for the total respondent pregnant mothers of Jimma Zone: $1^{\text {st }}$ quartile $=350$ Eth.birr., $2^{\text {nd }}$ quartile $=500$ Eth.birr, and $3^{\text {rd }}$ quartile $=700$ Eth.birr.

A total of 809 (52.3\%), 495 (64.3\%) urban and 314 (40.5\%) rural, respondents reported that they had autonomy in the decisions of household expenditure. With regard to household monthly expenditure, 350 Eth.birr, 500 Eth.birr, and 700 Eth.birr were the $25^{\text {th }}, 50^{\text {th }}$ (median) and $75^{\text {th }}$ percentiles of monthly household expenditure of the studied mothers. The household expenditure of a total of 454 (31.3\%) of participants, 229 (31.1\%) urban and 225 (31.5\%) rural residents, fall between 351 and 500 Eth. birr. Regarding solid waste disposal system, more than half (67.3\%) of the mothers, $638(82.9 \%)$ of urban and $402(51.9 \%)$ of rural resident, reported that they had safe solid waste disposal system (Table 1$)$.

Majority (84.3\%) of, 632 (82.1\%) urban and 669 (86.4\%) rural, mothers reported that their main source of drinking water was not safe during their first visit for ANC. Similarly 821 (53.2\%), 389 (50.5\%) urban and 432 
(55.9\%) rural resident, mothers reported that they were using open field/pit latrine facility. A total of 1235 (79.9\%), 618 (80.3\%) urban and 617 (79.5\%) rural, mothers had no health problems at booking for ANC. Additionally, m half (52.2\%) of the respondent, 348 (45.2\%) urban and 459 (59.1\%) rural, mothers booked at the spring "Belg" season (March-May) of the year (Table 1). It is the season between the dry season (winter "Bega": December-February) and rainy season (summer' "Kiremt": June-August) of the year. Autumn "Tseday" season is in the month of September to November of the year in Ethiopia.

\subsection{Prevalence of BMI Categories of Pregnant Women of Urban versus Rural Residents at Booking for ANC}

In this study, the mean BMI of the pregnant mothers at the first visit for ANC was $21.67 \mathrm{~kg} / \mathrm{m}^{2}(\mathrm{SD}=2.47)$ and ranges from 14 to $33 \mathrm{~kg} / \mathrm{m}^{2}$. Majority, $60.8 \%$ urban and $60.2 \%$ rural residents, had normal BMI at the time of booking for ANC in the selected governmental health centers (Woredas) of Jimma Zone, while the remaining considerable number of pregnant mothers, 172 (22.3\%) urban and 211 (27.2\%) rural residents, had low BMI; and 130 (16.9\%) of urban and 98 (12.6\%) of rural pregnant mothers had high BMI at the time of booking. Statistically significant difference was observed in the distribution of the proportions of BMI categories of the respondent mothers by their place of residence/different Woredas included in the study ( $\mathrm{P}<0.05$ and $<0.001$, respectively) (Table 2). The Woredas in decreasing order of the proportions of low BMI of the pregnant mothers at booking for ANC in the selected health centers (on static/outreach base) were Kersa (37.6\%), Omonada (33.3\%), Mana (28.5\%), Gera (19.2\%), Shebe Sombo (17.4\%) and Seka Chekorsa (12.5\%). Whereas, the order by proportions of high BMI of the respondents was Gera (23.5\%), Omonada (22.1\%), Shebe Sombo (14.7\%), Seka Chekorsa (10.2\%), Mana (9.4\%) and Kersa (8.5\%) (Table 2).

\subsection{Socio-Demographic/Economic Risk Factors for Low and High BMI of Pregnant Women of Urban and Rural Residents}

As shown in Table 3, statistically significant difference in the distribution of the proportions of BMI status of

Table 2. BMI of respondent pregnant mothers by residence/Woreda in governmental health centers of Jimma Zone, Southwest Ethiopia, March-October 2011.

\begin{tabular}{|c|c|c|c|c|c|}
\hline & \multicolumn{3}{|c|}{ BMI (n = 1546) } & \multirow{3}{*}{$\chi^{2 \mathrm{a}}$} & \multirow{3}{*}{ P-value } \\
\hline & Low BMI & Normal BMI & High BMI & & \\
\hline & No (\%) & No (\%) & No (\%) & & \\
\hline \multicolumn{6}{|l|}{ Residence } \\
\hline Urban & $172(22.3)$ & $468(60.8)$ & 130 (16.9) & \multirow{3}{*}{8.44} & \multirow{3}{*}{$0.015^{*}$} \\
\hline Rural & $211(27.2)$ & $467(60.2)$ & 98 (12.6) & & \\
\hline Total & 383 (24.8) & 935 (60.5) & $228(14.7)$ & & \\
\hline \multicolumn{6}{|l|}{ Woredas } \\
\hline Gera & $50(19.2)$ & 149 (57.3) & $61(23.5)$ & \multirow{7}{*}{116.40} & \multirow{7}{*}{$0.000^{*}$} \\
\hline Mana & 73 (28.5) & $159(62.1)$ & $24(9.4)$ & & \\
\hline Shebe Sombo & 45 (17.4) & 175 (67.8) & 38 (14.7) & & \\
\hline Seka Chekorsa & 32 (12.5) & $198(77.3)$ & $26(10.2)$ & & \\
\hline Kersa & 97 (37.6) & 139 (53.9) & $22(8.5)$ & & \\
\hline Omonada & 86 (33.3) & $115(44.6)$ & $57(22.1)$ & & \\
\hline Total & 383 (24.8) & 935 (60.5) & $228(14.7)$ & & \\
\hline
\end{tabular}

${ }^{\mathrm{a}}$ Chi-square test for counts; ${ }^{*}$ Significant at $\mathrm{p}<0.05$. 
Table 3. BMI of urban respondent pregnant mothers by socio-demographic/economic characteristics in governmental health centers of Jimma Zone, Southwest Ethiopia, March-October 2011.

\begin{tabular}{|c|c|c|c|c|c|}
\hline \multirow{3}{*}{ Characteristics } & \multicolumn{3}{|c|}{ BMI $(\mathrm{n}=770)$} & \multirow{3}{*}{$\chi^{2 \mathrm{a}}$} & \multirow{3}{*}{ P-value } \\
\hline & Low BMI & Normal BMI & High BMI & & \\
\hline & No (\%) & No (\%) & No (\%) & & \\
\hline \multicolumn{6}{|l|}{ Age (years) } \\
\hline $15-19$ & 35 (24.6) & $90(63.4)$ & $17(12.0)$ & \multirow{3}{*}{4.272} & \multirow{3}{*}{0.370} \\
\hline $20-24$ & $68(23.2)$ & $174(59.4)$ & $51(17.4)$ & & \\
\hline $25+$ & 66 (19.9) & $203(61.3)$ & $62(18.7)$ & & \\
\hline \multicolumn{6}{|l|}{ Education } \\
\hline Illiterate & $66(21.0)$ & $202(64.1)$ & 47 (14.9) & \multirow{3}{*}{12.232} & \multirow{3}{*}{$0.016^{*}$} \\
\hline Read and Write & $72(27.4)$ & $153(58.2)$ & $38(14.4)$ & & \\
\hline Primary and above & 30 (16.9) & $107(60.1)$ & $41(23.0)$ & & \\
\hline \multicolumn{6}{|l|}{ Parity } \\
\hline Nullipara & $86(22.8)$ & 237 (62.9) & $54(14.3)$ & \multirow{3}{*}{6.860} & \multirow{3}{*}{0.143} \\
\hline Primipara & 23 (16.9) & $87(64.0)$ & $26(19.1)$ & & \\
\hline Multipara & $59(24.1)$ & 137 (55.9) & $49(20.0)$ & & \\
\hline \multicolumn{6}{|l|}{ Gestation weeks (period) } \\
\hline $1^{\text {st }}$ Trimester & $19(28.4)$ & $39(58.2)$ & $9(13.4)$ & \multirow{3}{*}{27.625} & \multirow{3}{*}{$0.000^{*}$} \\
\hline $2^{\text {nd }}$ Trimester & $112(23.9)$ & 299 (63.9) & 57 (12.2) & & \\
\hline $3^{\text {rd }}$ Trimester & $41(17.4)$ & $130(55.3)$ & $64(27.2)$ & & \\
\hline \multicolumn{6}{|l|}{ Autonomy } \\
\hline No & $60(21.8)$ & $172(62.5)$ & $43(15.6)$ & \multirow{2}{*}{0.665} & \multirow{2}{*}{0.717} \\
\hline Yes & $112(22.6)$ & $296(59.8)$ & 87 (17.6) & & \\
\hline \multicolumn{6}{|l|}{ Monthly household expenditure } \\
\hline$\leq 350$ Eth.birr & $24(22.2)$ & $68(63.0)$ & $16(14.8)$ & \multirow{4}{*}{15.697} & \multirow{4}{*}{$0.015^{*}$} \\
\hline 351 - 500 Eth.birr & $61(26.6)$ & $145(63.3)$ & $23(10.0)$ & & \\
\hline 501 - 700 Eth.birr & 45 (19.5) & $145(62.8)$ & $41(17.7)$ & & \\
\hline$>700$ Eth.birr & $34(20.1)$ & $95(56.2)$ & $40(23.7)$ & & \\
\hline \multicolumn{6}{|l|}{ Solid waste disposal system } \\
\hline Unsafe & 27 (20.5) & $83(62.9)$ & $22(16.7)$ & \multirow{2}{*}{0.373} & 0830 \\
\hline Safe & $145(22.7)$ & $385(60.3)$ & $108(16.9)$ & & 0.000 \\
\hline Safety of drinking water & & & & & \\
\hline Yes & $30(21.7)$ & 77 (55.8) & $31(22.5)$ & 3.815 & 0.148 \\
\hline No & $142(22.5)$ & 391 (61.9) & 99 (15.7) & 3.010 & 0.140 \\
\hline Latrine facility & & & & & \\
\hline Open field/pit system & $80(20.6)$ & $246(63.2)$ & $63(16.2)$ & 2108 & 0.349 \\
\hline Covered pit/water carriage system & $92(24.1)$ & $222(58.3)$ & $67(17.6)$ & 2.108 & 0.349 \\
\hline Health problems at booking & & & & & \\
\hline Yes & $24(15.8)$ & $105(69.1)$ & $23(15.1)$ & 6.126 & $0.047^{*}$ \\
\hline No & $148(23.9)$ & $363(58.7)$ & $107(17.3)$ & 0.120 & 0.041 \\
\hline Season at booking & & & & & \\
\hline Tseday & $18(23.1)$ & $50(64.1)$ & $10(12.8)$ & & \\
\hline Bega & $26(21.0)$ & 82 (66.1) & 16 (12.9) & 4075 & 0666 \\
\hline Belg & 81 (23.3) & 205 (58.9) & 62 (17.8) & (1.08 & 0.000 \\
\hline Kiremt & 47 (21.4) & 131 (59.5) & 42 (19.1) & & \\
\hline
\end{tabular}

${ }^{\mathrm{a}}$ Chi-square test for counts; ${ }^{*}$ Significant at $\mathrm{p}<0.05$. 
urban pregnant mothers by education level $(\mathrm{p}<0.05)$, gestational age $(\mathrm{p}<0.001)$, household expenditure $(\mathrm{p}<$ $0.05)$, and health problems at booking $(\mathrm{p}<0.05)$ was observed.

The cross tabulation (Table 4) made for the rural residents revealed also the presence of statistically signifi-

Table 4. BMI of rural respondent pregnant mothers by socio-demographic/economic characteristics in governmental health centers of Jimma Zone, Southwest Ethiopia, March-October 2011.

\begin{tabular}{|c|c|c|c|c|c|}
\hline \multirow{3}{*}{ Characteristics } & \multicolumn{3}{|c|}{ BMI $(n=776)$} & \multirow{3}{*}{$\chi^{2 \mathrm{a}}$} & \multirow{3}{*}{ P-value } \\
\hline & Low BMI & Normal BMI & High BMI & & \\
\hline & No (\%) & No (\%) & No (\%) & & \\
\hline \multicolumn{6}{|l|}{ Age (years) } \\
\hline & $32(27.8)$ & $72(62.6)$ & $11(9.6)$ & \multirow{3}{*}{1.471} & \multirow{3}{*}{0.832} \\
\hline $20-24$ & $74(26.5)$ & $166(59.5)$ & $39(14.0)$ & & \\
\hline $25+$ & 105 (27.5) & 229 (59.9) & $48(12.6)$ & & \\
\hline \multicolumn{6}{|l|}{ Education } \\
\hline Illiterate & $162(26.5)$ & $371(60.7)$ & $78(12.8)$ & \multirow{3}{*}{5.701} & \multirow{3}{*}{0.223} \\
\hline Read and write & $25(36.8)$ & $33(48.5)$ & $10(14.7)$ & & \\
\hline Primary and above & $22(25.0)$ & $58(65.9)$ & $8(9.1)$ & & \\
\hline \multicolumn{6}{|l|}{ Parity } \\
\hline Nullipara & $78(25.7)$ & $184(60.5)$ & $42(13.8)$ & \multirow{3}{*}{2.221} & \multirow{3}{*}{0.695} \\
\hline Primipara & $33(28.4)$ & $65(56.0)$ & $18(15.5)$ & & \\
\hline Multipara & $93(27.6)$ & $206(61.1)$ & $38(11.3)$ & & \\
\hline \multicolumn{6}{|l|}{ Gestation weeks (period) } \\
\hline $1^{\text {st }}$ Trimester & $28(35.4)$ & $42(53.2)$ & $9(11.4)$ & \multirow{3}{*}{16.659} & \multirow{3}{*}{$0.002^{*}$} \\
\hline $2^{\text {nd }}$ Trimester & $140(30.8)$ & $262(57.6)$ & $53(11.6)$ & & \\
\hline $3^{\text {rd }}$ Trimester & $43(17.8)$ & $163(67.4)$ & $36(14.9)$ & & \\
\hline \multicolumn{6}{|l|}{ Autonomy } \\
\hline No & $120(26.0)$ & $279(60.4)$ & $63(13.6)$ & \multirow{2}{*}{1.548} & \multirow{2}{*}{0.461} \\
\hline Yes & $91(29.0)$ & 188 (59.9) & 35 (11.1) & & \\
\hline \multicolumn{6}{|l|}{ Monthly household expenditure } \\
\hline$\leq 350$ Eth.birr & $59(20.8)$ & 195 (68.7) & $30(10.6)$ & \multirow{4}{*}{15.979} & \multirow{4}{*}{$0.014^{*}$} \\
\hline 351 - 500 Eth. birr & $69(30.7)$ & $131(58.2)$ & $25(11.1)$ & & \\
\hline 501 - 700 Eth.birr & $49(37.4)$ & $70(53.4)$ & $12(9.2)$ & & \\
\hline >700 Eth.birr & $21(28.4)$ & $42(56.8)$ & $11(14.9)$ & & \\
\hline \multicolumn{6}{|l|}{ Solid waste disposal system } \\
\hline Unsafe & $102(27.3)$ & $223(59.8)$ & $48(12.9)$ & \multirow{2}{*}{0.046} & 0977 \\
\hline Safe & $109(27.1)$ & $243(60.4)$ & $50(12.4)$ & & $0.97 /$ \\
\hline Safety of drinking water & & & & & \\
\hline Yes & $26(24.8)$ & $64(61.0)$ & $15(14.3)$ & 0516 & 0773 \\
\hline No & $184(27.5)$ & $402(60.1)$ & $83(12.4)$ & 0.510 & $0.7 / 3$ \\
\hline Latrine facility & & & & & \\
\hline Open field/pit system & $108(25.0)$ & $265(61.3)$ & 59 (13.7) & 2663 & 0264 \\
\hline Covered pit/water carriage system & $102(29.9)$ & $200(58.7)$ & $39(11.4)$ & 2.005 & 0.204 \\
\hline Health Problems at booking & & & & & \\
\hline Yes & $40(25.2)$ & $103(64.8)$ & $16(10.1)$ & ᄀ & (25 0 \\
\hline No & $171(27.7)$ & $364(59.0)$ & $82(13.3)$ & 2.050 & 0.359 \\
\hline Season at booking & & & & & \\
\hline Tseday & $11(36.7)$ & $13(43.3)$ & $6(20.0)$ & & \\
\hline Bega & 58 (31.9) & $106(58.2)$ & $18(9.9)$ & 13.398 & $0.037^{*}$ \\
\hline Belg & 107 (23.3) & $294(64.1)$ & 58 (12.6) & & \\
\hline Kiremt & 35 (33.3) & $54(51.4)$ & $16(15.2)$ & & \\
\hline
\end{tabular}

${ }^{\mathrm{a}}$ Chi-square test for counts; "Significant at $\mathrm{p}<0.05$. 
cant difference in the distribution of the BMI status of the rural pregnant women by gestational age $(\mathrm{p}<0.01)$, household expenditure $(\mathrm{p}<0.05)$, and season at booking $(\mathrm{p}<0.05)$.

In this study, a multinomial logistic regression analysis was employed using enter method to identify important independently associated factors for low BMI and high BMI of the studied urban and rural pregnant women. In the multivariate analysis, all of the independent variables of the study were entered. These variables were age, education level, parity, gestation period, autonomy, household expenditure, solid waste disposal system, safety of drinking water, latrine facility, health problem and season at booking for ANC (Table 5 and Table 6).

In the urban pregnant mothers (Table 5 and its foot note), only mother's educational level and gestation period showed a statistically significant $(\mathrm{p}<0.05)$ result of both tests (Likelihood ratio test and Wald test) shown in the SPSS output of the multivariate multinomial logistic regression analysis done to see the separate effect of each independent variable on the response variable (BMI) by controlling the confounding effect of the other independent variables. Based on the model comparing urban pregnant mothers of high BMI group with normal BMI group, urban pregnant mothers with primary and above education level (AOR = 2.13, 95\% CI, 1.21 - 3.74) were more likely to be with high BMI than the illiterates when the confounding effect of gestation period, health problems at booking and the other independent variables included in the model was controlled. Similarly, the mothers in higher gestation week ( $3^{\text {rd }}$ trimester) were more likely ( $\mathrm{AOR}=3.21,95 \% \mathrm{CI}, 2.02-5.9$ ) to be with high BMI than in lower gestation weeks $\left(2^{\text {nd }}\right.$ trimester) when the other independent variables were controlled. Therefore, primary and above education level and $3^{\text {rd }}$ trimester gestation period of mothers were found to be independently associated important factors for high BMI of the urban pregnant mothers at the time of their booking for ANC.

In the rural pregnant mothers (Table 6 and its foot note), only mother's gestation period and monthly household expenditure had a statistically significant $(\mathrm{p}<0.05)$ result of both tests (Likelihood ratio test and Wald test) in the multivariate multinomial logistic regression analysis. After controlling for the confounding effect of gestation period, health problems at booking and the other independent variables, the model comparing low BMI group to normal BMI group of rural pregnant mothers showed that low BMI was more likely to occur in rural pregnant mothers who had higher monthly household expenditure (351 - 500 Eth.birr, AOR $=1.89,95 \%$ CI, 1.21 - 2.95; 501 - 700 Eth.birr, AOR = 2.80, 95\% CI, 1.67 - 4.72; $701-1000$ Eth.birr, AOR $=2.07,95 \%$ CI, 1.07 - 4.02) than those spending less than or equal to 350 Eth.birr per month. Likewise, low BMI was less likely to happen in third trimester of pregnancy (AOR $=0.44,95 \% \mathrm{CI}, 0.29-0.69$ ) than second trimester. Thus, higher monthly household expenditure and $3^{\text {rd }}$ trimester gestation period of mothers were found to be independently associated important factors for low BMI of the rural pregnant mothers at the time of their booking for ANC.

\section{Discussion}

This study determined the prevalence and identify important independent socio-demographic/economic risk factors of low and high BMI among urban versus rural pregnant women at their first visit or booking for antenatal care in governmental health centers of Jimma Zone, Southwest Ethiopia.

Similar to other developing countries [9], the pregnant mothers visited health institutions and booked for ANC in the late weeks of gestation. Majority (59.7\%) of the pregnant mothers, urban (60.8\%) and rural (58.6\%) residents, came for their $1^{\text {st }}$ ANC visit in the second trimester of pregnancy. However, only $9.4 \%$ of the pregnant mothers, $8.7 \%$ of urban and $10.2 \%$ of rural residents, came in their $1^{\text {st }}$ trimester for the $1^{\text {st }}$ ANC booking.

Majority of, $60.8 \%$ urban and $60.2 \%$ rural resident, pregnant mothers had normal BMI at the time of their booking for ANC (on static/outreach basis) in the selected governmental health centers (Woredas) of Jimma Zone. Prevalence of low BMI was $24.8 \%$ among all of the studied pregnant mothers, lesser (22.3\%) in urban than rural (27.2\%) residents; whereas the prevalence of high BMI was $14.7 \%$ among all of the studied pregnant mothers, higher in urban (16.9\%) than rural (12.6\%) residents, at the time of booking. Compared to these findings, lower prevalence of PEM was reported in the study conducted on pregnant women recruited from antenatal clinics in Khon Kaen province (15.1\% in $1^{\text {st }}$ trimester) in Thailand in 2003 [19], and Dar es Salaam, urban Tanzania, (overall $2.9 \%$ and $5.6 \%$ in $1^{\text {st }}$ trimester) in 2003 and 2004 [9]. In the Nigeria's study [18], the mean BMI was significantly lower in rural than urban pregnant mothers. On the other hand, the prevalence of BMI $\geq 25$ (overweight and obesity in $<14$ weeks of gestation) in Dar es Salam (30.9\% in 2004) was greater than the findings of the current study of our settings $(12.3 \%$ in the urban and $11.6 \%$ in the rural mothers in $\leq 24$ weeks of gestation). These differences might be due to socio-economic, cultural and genetic differences. Also, statistically 
Table 5. Estimates of unadjusted and adjusted odds ratio from multinomial logistic regression model for BMI of urban respondent pregnant mothers in governmental health centers of Jimma Zone, Southwest Ethiopia, March-October 2011.

\begin{tabular}{|c|c|c|c|c|}
\hline \multirow{3}{*}{ Characteristics } & \multicolumn{4}{|c|}{ BMI Category } \\
\hline & \multicolumn{2}{|c|}{ Low BMI } & \multicolumn{2}{|c|}{ High BMI } \\
\hline & COR $(95 \%$ CI $)$ & AOR $(95 \% \mathrm{CI})$ & COR $(95 \% \mathrm{CI})$ & AOR (95\% CI) \\
\hline \multicolumn{5}{|l|}{ Age (years) } \\
\hline $15-19$ (Ref) & 1.00 & 1.00 & 1.00 & 1.00 \\
\hline $20-24$ & $1.01(0.62$ - 1.63) & $0.99(0.59-1.65)$ & $1.55(0.85-2.84)$ & $1.70(0.83-3.51)$ \\
\hline $25+$ & $0.84(0.52-1.35)$ & $0.64(0.34-1.18)$ & $1.62(0.90-2.92)$ & $1.05(0.47-2.33)$ \\
\hline \multicolumn{5}{|l|}{ Education } \\
\hline Illiterate (Ref) & 1.00 & 1.00 & 1.00 & 1.00 \\
\hline Read and Write & $1.44(0.97-2.14)$ & $1.21(0.77-1.90)$ & $1.07(0.66-1.72)$ & $0.94(0.54-1.64)$ \\
\hline Primary and above & $0.86(0.53-1.40)$ & $0.89(0.52-1.53)$ & $1.65(1.02-2.66)^{*}$ & $2.13(1.21-3.74)^{* *}$ \\
\hline \multicolumn{5}{|l|}{ Parity } \\
\hline Nullipara & $0.84(0.57-1.25)$ & $0.66(0.39-1.12)$ & $0.64(0.41-0.99)^{*}$ & $0.50(0.27-0.90)^{*}$ \\
\hline Primipara & $0.61(0.35-1.07)$ & $0.50(0.27-0.94)^{*}$ & $0.84(0.48-1.44)$ & $0.60(0.31-1.15)$ \\
\hline Multipara (Ref) & 1.00 & 1.00 & 1.00 & 1.00 \\
\hline \multicolumn{5}{|l|}{ Gestation weeks (period) } \\
\hline $1^{\text {st }}$ Trimester & $1.30(0.72-2.35)$ & $1.66(0.86-3.19)$ & $1.21(0.56-2.64)$ & $0.81(0.31-2.10)$ \\
\hline $2^{\text {nd }}$ Trimester (Ref) & 1.00 & 1.00 & 1.00 & 1.00 \\
\hline $3^{\text {rd }}$ Trimester & $0.84(0.56-1.27)$ & $0.85(0.54-1.33)$ & $2.58(1.71-3.90)^{* * *}$ & $3.21(2.02-5.09)^{* * *}$ \\
\hline \multicolumn{5}{|l|}{ Autonomy } \\
\hline No & $0.92(0.64-1.33)$ & $0.93(0.60-1.46)$ & $0.85(0.56-1.28)$ & $1.00(0.60-1.68)$ \\
\hline Yes (Ref) & 1.00 & 1.00 & 1.00 & 1.00 \\
\hline \multicolumn{5}{|l|}{ Monthly household expenditure } \\
\hline$\leq 350$ Eth.birr & 1.00 & 1.00 & 1.00 & 1.00 \\
\hline 351 - 500 Eth. birr & $1.19(0.69-2.07)$ & $1.12(0.62-2.04)$ & $0.67(0.34-1.36)$ & $0.78(0.36-1.68)$ \\
\hline 501 - 700 Eth.birr & $0.88(0.50-1.56)$ & $0.83(0.45-1.54)$ & $1.20(0.63-2.29)$ & $1.68(0.82-3.44)$ \\
\hline >700 Eth.birr & $1.01(0.55$ - 1.86) & $1.02(0.52-2.01)$ & $1.79(0.93-3.46)$ & $2.06(0.97-4.38)$ \\
\hline \multicolumn{5}{|l|}{ Solid waste disposal system } \\
\hline Unsafe & $0.86(0.54-1.39)$ & $1.16(0.68-2.00)$ & $0.95(0.56-1.58)$ & $1.12(0.62-2.02)$ \\
\hline Safe (Ref) & 1.00 & 1.00 & 1.00 & 1.00 \\
\hline \multicolumn{5}{|l|}{ Safety of drinking water } \\
\hline Yes (Ref) & 1.00 & 1.00 & 1.00 & 1.00 \\
\hline No & $0.93(0.59-1.48)$ & $1.16(0.67-2.00)$ & $0.63(0.39-1.01)$ & $0.77(0.42-1.41)$ \\
\hline \multicolumn{5}{|l|}{ Latrine facility } \\
\hline Open field/pit system & $0.79(0.55-1.11)$ & $0.67(0.45-1.00)$ & $0.85(0.58-1.25)$ & $1.00(0.63-1.59)$ \\
\hline Covered pit/water carriage system (Ref) & 1.00 & 1.00 & 1.00 & 1.00 \\
\hline \multicolumn{5}{|l|}{ Health Problems at booking } \\
\hline Yes & $0.56(0.35-0.91)^{*}$ & $0.56(0.32-0.97)^{*}$ & $0.74(0.45-1.23)$ & $0.75(0.42-1.34)$ \\
\hline No (Ref) & 1.00 & 1.00 & 1.00 & 1.00 \\
\hline \multicolumn{5}{|l|}{ Season at booking } \\
\hline Tseday & $1.00(0.53$ - 1.89) & $1.06(0.54-2.08)$ & $0.62(0.29-1.34)$ & $0.46(0.19-1.11)$ \\
\hline Bega & $0.88(0.51-1.54)$ & $0.82(0.44-1.54)$ & $0.61(0.32-1.15)$ & $0.62(0.30-1.27)$ \\
\hline Belg & $1.10(0.72$ - 1.68) & $1.08(0.68-1.72)$ & $0.94(0.60-1.48)$ & $0.82(0.48-1.37)$ \\
\hline Kiremt (Ref) & 1.00 & 1.00 & 1.00 & 1.00 \\
\hline
\end{tabular}

Normal BMI is the reference for BMI categories; COR = Crude Odds Ratio; AOR = Adjusted Odds Ratio; Wald test: ${ }^{*} \mathrm{p}<0.05 ;{ }^{* *} \mathrm{p}<0.01 ;{ }^{* * *} \mathrm{p}<$ 0.001; The standard error for the "b" coefficients of all independent variables of the multivariate model was not larger than 2.0; The categorical variables of age, education, parity, gestation week, autonomy, household expenditure, solid waste disposal system, safety of drinking water, latrine facility, health problems at booking and season at booking were adjusted in the final model; The cases to variables ratio (710:19) was 37.4 to 1; Model Fitting Information: the probability of the final model chi-square (94.89) was 0.000; The likelihood ratio test was significant only for Education $\left(\mathrm{x}^{2}=\right.$ $12.31, \mathrm{p}<0.05)$, gestation week $\left(\mathrm{x}^{2}=35.46, \mathrm{p}<0.001\right)$ and household expenditure $\left(\mathrm{x}^{2}=14.84, \mathrm{p}<0.05\right)$; The proportional by chance accuracy rate was $0.218^{2}+0.618^{2}+0.163^{2}=0.456$; The proportional by chance accuracy criteria was $57.4 \%$; The overall correct classification accuracy rate was $63.4 \%$ (low BMI group 3.2\%, normal BMI group 97.9\% and high BMI group 12.9\%), which is not greater than $2 \%$, when compared to the accuracy rate after omitting outliers (63.8\%). Hence, the model with all cases was interpreted in this analysis. 
Table 6. Estimates of unadjusted and adjusted odds ratio from multinomial logistic regression model for BMI of rural respondent pregnant mothers in governmental health centers of Jimma Zone, Southwest Ethiopia, March-October 2011.

\begin{tabular}{|c|c|c|c|c|}
\hline \multirow{3}{*}{ Characteristics } & \multicolumn{4}{|c|}{ BMI Category } \\
\hline & \multicolumn{2}{|c|}{ Low BMI } & \multicolumn{2}{|c|}{ High BMI } \\
\hline & COR $(95 \% \mathrm{CI})$ & AOR $(95 \% \mathrm{CI})$ & COR $(95 \%$ CI $)$ & AOR (95\% CI) \\
\hline \multicolumn{5}{|l|}{ Age (years) } \\
\hline 15 - 19 (Ref) & 1.00 & 1.00 & 1.00 & 1.00 \\
\hline $20-24$ & $1.00(0.61-1.65)$ & $1.14(0.63-2.04)$ & $1.54(0.75-3.17)$ & $1.08(0.48-2.47)$ \\
\hline $25+$ & $1.03(0.64-1.66)$ & $1.34(0.71-2.55)$ & $1.37(0.68-2.78)$ & $1.72(0.72-4.09)$ \\
\hline \multicolumn{5}{|l|}{ Education } \\
\hline Illiterate (Ref) & 1.00 & 1.00 & 1.00 & 1.00 \\
\hline Read and Write & $1.74(0.10-3.01)$ & $1.68(0.87-3.24)$ & $1.44(0.68-3.05)$ & $1.61(0.66-3.96)$ \\
\hline Primary and above & $0.87(0.51-1.47)$ & $0.96(0.52-1.77)$ & $0.66(0.30-1.43)$ & $0.83(0.36-1.93)$ \\
\hline \multicolumn{5}{|l|}{ Parity } \\
\hline Nullipara & $0.94(0.66-1.35)$ & $1.08(0.65-1.78)$ & $1.24(0.76-2.00)$ & $2.00(1.01-3.95)^{*}$ \\
\hline Primipara & $1.13(0.69-1.83)$ & $1.25(0.70-2.24)$ & $1.50(0.80-2.81)$ & $2.40(1.10-5.22)^{*}$ \\
\hline Multipara (Ref) & 1.00 & 1.00 & 1.00 & 1.00 \\
\hline \multicolumn{5}{|l|}{ Gestation weeks (period) } \\
\hline $1^{\text {st }}$ Trimester & $1.25(0.74-2.10)$ & $1.50(0.82-2.76)$ & $1.06(0.49-2.31)$ & $0.76(0.27-2.13)$ \\
\hline $2^{\text {nd }}$ Trimester (Ref) & 1.00 & 1.00 & 1.00 & 1.00 \\
\hline $3^{\text {rd }}$ Trimester & $0.49(0.33-0.73)^{* * *}$ & $0.44(0.29-0.69)^{* * *}$ & $1.09(0.69-1.74)$ & $1.06(0.62-1.82)$ \\
\hline \multicolumn{5}{|l|}{ Autonomy } \\
\hline No & $0.89(0.64-1.24)$ & $0.80(0.55-1.17)$ & $1.21(0.77-1.91)$ & $1.12(0.66-1.90)$ \\
\hline Yes (Ref) & 1.00 & 1.00 & 1.00 & 1.00 \\
\hline \multicolumn{5}{|l|}{ Monthly household expenditure } \\
\hline$\leq 350$ Eth.birr & 1.00 & 1.00 & 1.00 & 1.00 \\
\hline 351 - 500 Eth. birr & $1.74(1.15-2.63)^{* *}$ & $1.89(1.21-2.95)^{* *}$ & $1.24(0.70-2.21)$ & $1.46(0.80-2.66)$ \\
\hline 501 - 700 Eth.birr & $2.31(1.45-3.69)^{* * *}$ & $2.80(1.67-4.72)^{* * *}$ & $1.11(0.54-2.30)$ & $1.51(0.69-3.26)$ \\
\hline$>700$ Eth.birr & $1.65(0.91-3.01$ & $2.07(1.07-4.02)^{*}$ & $1.70(0.79-3.67)$ & $1.88(0.81-4.39)$ \\
\hline \multicolumn{5}{|l|}{ Solid waste disposal system } \\
\hline Unsafe & $1.02(0.74-1.41)$ & $1.11(0.75-1.64)$ & $1.05(0.68-1.62)$ & $0.93(0.54-1.60)$ \\
\hline Safe (Ref) & 1.00 & 1.00 & 1.00 & 1.00 \\
\hline \multicolumn{5}{|l|}{ Safety of drinking water } \\
\hline Yes (Ref) & 1.00 & 1.00 & 1.00 & 1.00 \\
\hline No & $1.13(0.69-1.84)$ & $1.25(0.69-2.26)$ & $0.88(0.48-1.62)$ & $1.42(0.64-3.14)$ \\
\hline \multicolumn{5}{|l|}{ Latrine facility } \\
\hline Open field/pit system & $0.80(0.58-1.11)$ & $0.70(0.48-1.04)$ & $1.14(0.73-1.78)$ & $0.99(0.58-1.71)$ \\
\hline Covered pit/water carriage system (Ref) & 1.00 & 1.00 & 1.00 & 1.00 \\
\hline \multicolumn{5}{|l|}{ Health Problems at booking } \\
\hline Yes & $0.83(0.55-1.24)$ & $0.84(0.53-1.32)$ & $0.69(0.39-1.23)$ & $0.73(0.37-1.43)$ \\
\hline No (Ref) & 1.00 & 1.00 & 1.00 & 1.00 \\
\hline \multicolumn{5}{|l|}{ Season at booking } \\
\hline Tseday & $1.31(0.53-3.24)$ & $1.41(0.52-3.80)$ & $1.56(0.51-4.76)$ & $2.47(0.72-8.51)$ \\
\hline Bega & $0.84(0.50-1.44)$ & $1.08(0.58-2.02)$ & $0.57(0.27-1.21)$ & $0.84(0.34-2.07)$ \\
\hline Belg & $0.56(0.35-0.91)^{*}$ & $0.65(0.37-1.14)$ & $0.67(0.36-1.24)$ & $0.82(0.38-1.78)$ \\
\hline Kiremt (Ref) & 1.00 & 1.00 & 1.00 & 1.00 \\
\hline
\end{tabular}

Normal BMI is the reference for BMI categories; COR = Crude Odds Ratio; AOR = Adjusted Odds Ratio; Wald test: ${ }^{*} \mathrm{p}<0.05 ;{ }^{* *} \mathrm{p}<0.01 ;{ }^{* * *} \mathrm{p}<$ 0.001; The standard error for the "b" coefficients of all independent variables of the multivariate model was not larger than 2.0; The categorical variables of age, education, parity, gestation week, autonomy, household expenditure, solid waste disposal system, safety of drinking water, latrine facility, health problems at booking and season at booking were adjusted in the final model; The cases to variables ratio (683:19) was 35.9 to 1; Model Fitting Information: the probability of the final model chi-square (69.36) was 0.001 ; The likelihood ratio test was significant only for gestation week $\left(\mathrm{x}^{2}=19.58, \mathrm{p}<0.01\right)$ and household expenditure $\left(\mathrm{x}^{2}=18.70, \mathrm{p}<0.01\right)$; The proportional by chance accuracy rate was $0.274^{2}+0.615^{2}+0.111^{2}=$ 0.466; The proportional by chance accuracy criteria was 58.3\%; The overall correct classification accuracy rate was $64.1 \%$ (low BMI group23.5\%, normal BMI group $93.8 \%$ and high BMI group $0 \%$ ), which is not greater than $2 \%$, when compared to the accuracy rate after omitting outliers (64.3\%). Hence, the model with all cases was interpreted in this analysis. 
significant difference was observed in the distribution of the proportions of BMI categories of the respondent mothers by their place of residence $(p<0.05)$ and different Woredas (health centers) $(p<0.001)$ included in the current study.

Compared to the PEM figure of the Thailand's and Dar es Salaam's studies [9] [19], the proportions of low BMI of the pregnant mothers at booking for ANC (on static/outreach basis) in the selected health centers or Woredas (Kersa (37.6\%), Omonada (33.3\%), Mana (28.5\%), Gera (19.2\%), Shebe Sombo (17.4\%)) were high except for one Woreda (Seka Chekorsa (12.5\%)). Along this, high BMI was found in considerable proportions of the pregnant mothers residing in these Woredas (Gera (23.5\%), Omonada (22.1\%), Shebe Sombo (14.7\%), Seka Chekorsa (10.2\%), Mana (9.4\%) and Kersa (8.5\%)). This has a great implication for the need of designing and implementing abnormal BMI prevention and controlling strategies in the pregnant women of the studied areas/ Jimma zone at large.

In our study, multiple multinomial logistic regression model was employed separately for the urban and rural mothers to identify independent predictors of their BMI status (categories). In both models categorical variables of age, education, parity, gestation week, autonomy, household expenditure, solid waste disposal system, safety of drinking water, latrine facility, health problems at booking and season at booking were adjusted.

In the urban pregnant mothers, only primary and above education level and $3^{\text {rd }}$ trimester gestation period of mothers were found to be important independently associated factors for high BMI of the urban pregnant mothers at the time of their booking for ANC. The urban pregnant mothers with primary and above education level were more likely to have high BMI than the illiterates. Similarly, the mothers in higher gestational weeks ( $3^{\text {rd }}$ trimester) were more likely to have high BMI than in lower gestational weeks $\left(2^{\text {nd }}\right.$ trimester). This finding is consistent with the finding of a study done in Nigeria that showed significantly lower mean BMI and higher PEM prevalence among the less educated (no formal and primary education) pregnant women [18], since the category in our study included the mothers with above primary level of education too. It is also supported by the finding of a cohort study done in Rio de Janeiro state, Brazil, showed that, in the first trimester, pregnant women who had a higher education level were more likely to gain more weight than recommended [25]. In Recife, Pernambuko, Brazil, a study also reported the association of excessive weight gain with schooling of pregnant women in the third trimester [26]. In the later study, excessive weight gain was common in all categories of baseline nutritional status, but was more frequent in the second trimester among women who were already overweight or obese upon entering pregnancy [26]. Inconsistent to these findings, in the Dar es Salam's study, obesity had no significant association with an increase in gestation weeks [9].

In the rural pregnant mothers, only higher monthly household expenditure and $3^{\text {rd }}$ trimester gestation period were found to be important independently associated important factors for low BMI of the rural pregnant mothers at the time of their booking for ANC after controlling for the confounding effect of the other variables. Consistent to Dar es Salam's study [9], low BMI was less likely to happen in third trimester of pregnancy than second trimester. But, low BMI was more likely to occur in mothers who had higher monthly household expenditure than those spending less than or equal to 350 Eth.birr per month. In contrary to this, in the Dar es Salam's study food purchasing power (money spent on food) was positively associated with obesity and inversely related to underweight in pregnant women [9]. The household expenditure might have been not directly related to purchase of food and dietary consumption of the mothers or households of the rural settings of our study.

Furthermore, unlike to our study, in the Dar es Salam's study [9], obesity was positively associated with age, parity, and inversely with health problem (HIV infection). underweight was positively associated with HIV status. This indicates the need for more strong studies to identify factors affecting BMI and weight gain during pregnancy and take evidence based measures to ensure the wellbeing of mothers and children of our settings in the future.

Generally, the study used adequate sample size and produced generalizable findings to the target population. However, the weaknesses of using secondary data (extracted weight and height from ANC cards of mothers) was observed in the study. The ANC records had some incomplete information which resulted a considerable number of missing values, for instance for LMP, and, hence, exclusion of such items of the questionnaires from the analysis were made. The BMI at booking (though, not specific measure of nutritional status of pregnant women) was used in the study regardless of the extent of gestation week retrieved also from the routine ANC cards of the mothers by adjusting it in the multivariate multinomial logistic regression models, which is an acceptable procedure in such cases. 


\section{Conclusions and Recommendations}

In conclusion, in this study, very low proportion of the urban and rural pregnant mothers booked for the first ANC in their $1^{\text {st }}$ trimester of pregnancy, while the majority booked in the $2^{\text {nd }}$ trimester. A considerable proportion of both urban and rural pregnant mothers had low BMI as well as high BMI. The prevalence of low BMI was higher in rural than urban pregnant mothers, whereas high BMI was higher in the urban than rural pregnant mothers. The decreasing order of the Woredas by proportions of low BMI of the pregnant mothers was Kersa, Omonada, Mana, Gera, Shebe Sombo, and Seka Chekorsa; but, the order by the proportions of high BMI of the respondents was Gera, Omonada, Shebe Sombo, Seka Chekorsa, Mana, and Kersa. Moreover, primary and above education level and $3^{\text {rd }}$ trimester gestation were found as important positively and independently associated factors for high BMI of the urban pregnant mothers; while, higher monthly household expenditure (positively) and $3^{\text {rd }}$ trimester gestation period (negatively) were found as important independently associated factors for low BMI of the rural pregnant mothers at the time of their booking for ANC. Hence, the health bureaus of the zone/Woredas/health facilities of the study area should strengthen delivery of health education to the community to enable pregnant women to book in health facilities for the first ANC in the recommended time $\left(1^{\text {st }}\right.$ trimester of pregnancy). The health workers in health facilities should be able to determine/document the BMI status of every pregnant woman at booking for ANC, monitor weight gain and offer relevant health and nutritional advise/care to clients in all of the subsequent visits during pregnancy. FMOH/regional/all concerned governmental and non-governmental organizations should design a strategy to introduce the culture of monitoring nutritional status (BMI status) in women of reproductive age in their pre-pregnancy and monitoring body weight in their pregnancy periods in the study area and the country at large. Finally, undertaking further studies using strong design on the issue is also advisable in different settings of the country at large.

\section{Competing Interests}

We, authors, declare that we do not have competing interests.

\section{Authors' Contributions}

C.H., T.D., and B.T. participated in the conception and development of proposal of the study, training of data collectors, pretest of instrument, coordination and supervision of data collection, data entry, cleaning, analysis and interpretation of the data. C.H. and B.T. drafted the manuscript. All authors involved in editing the first draft, and read and approved the submission of the final manuscript for publication.

\section{Acknowledgements}

We would like to thank Jimma University for funding the research project; authorities of Jimma Zone and study Woredas' health offices/health facilities, the study participants (pregnant mothers) and the data collectors (health facility staffs) for their unreserved cooperation during the data collection process in their settings.

\section{References}

[1] Girma, W. and Genebo, T. (2002) Determinants of the Nutritional Status of Mothers and Children in Ethiopia. Health and Nutrition Research Institute, Addis Ababa.

[2] Rahman, M.M. and Nasrin, S.O. (2009) Mothers’ Nutritional Status in an Impoverished Nation. Bangladesh. Journal of Nutrition and Wellness, 7, 7.

[3] Wolf, H. (1998) High Pre-Pregnancy Body-Mass Index. A Maternal-Fetal Risk Factor. NEJM, 338, 191-192. http://dx.doi.org/10.1056/NEJM199801153380310

[4] Balgir, R. (2009) Impact of Gender Bias on Health and Nutrition of the Tribal Women in Relation to Dynamics of Development in India. The Internet Journal of Biological Anthropology, 3, 15.

[5] World Health Organization (2002) World Health Report. WHO, Geneva.

[6] Food and Agriculture Organization of the United Nations (2004) Under Nourishment around the World. In: State of Food Insecurity in the World, Food and Agriculture Organization of the United Nations, Rome.

[7] Sachs, J.D. and Mc. Arthur, J.W. (2005) The Millennium Project: A Plan for Meeting the Millennium Development Goals. Lancet, 365, 347-353. http://dx.doi.org/10.1016/S0140-6736(05)70201-4 
[8] Salama, P., Spiegel, P., Talley, L. and Waldman, R. (2004) Lessons Learned from Complex Emergencies over Past Decade. Lancet, 364, 1801-1813. http://dx.doi.org/10.1016/S0140-6736(04)17405-9

[9] Villamor, E., Msamanga, G., Urassa, W., Petraro, P., Spiegelman, D., Hunter, D.J., et al. (2006) Trends in Obesity, Underweight, and Wasting among Women Attending Prenatal Clinics in Urban Tanzania, 1995-2004. American Journal of Clinical Nutrition, 83, 1387-1394.

[10] Muller, O. and Krawinkel, M. (2005) Malnutrition and Health in Developing Countries. CMAJ, 171, 279-293. http://dx.doi.org/10.1503/cmaj.050342

[11] Peña, M. and Bacalao, J. (2002) Malnutrition and Poverty. Annual Review of Nutrition, 22, 241-253. http://dx.doi.org/10.1146/annurev.nutr.22.120701.141104

[12] FDROE (2008) Population Census Commission. Summary and Statistical Report of the 2007 Population and Housing Census Results: Population Size by Age and Sex. Addis Ababa.

[13] MOPED (1999) Poverty Situation in Ethiopia. Welfare Unit, Addis Ababa.

[14] WHO (2005) Maternal Mortality in 2005: Estimates Developed by WHO, UNICEF, UNFPA and the World Bank. WHO, Geneva.

[15] Ethiopian Central Statistical Agency and ORC Macro (2006) Ethiopia Demographic and Health Survey 2005. Addis Ababa.

[16] Institute of Medicine (1992) Nutrition during Pregnancy and Lactation: An Implementation Guide. National Academy Press, Washington DC.

[17] Benda, Y., Chapman, V., Goldenberg, R.L., Chi, B.H., Vermund, S.H. and Stringer, J.S.A. (2007) Influence of Body Mass Index on Pregnancy Outcomes among HIV-Infected and HIV-Uninfected Zambian Women. Tropical Medicine \& International Health, 12, 856-861. http://dx.doi.org/10.1111/j.1365-3156.2007.01857.x

[18] Okwu, G.N., Ukoha, A., Nwachukwu, N. and Agha, N.C. (2007) Studies on the Predisposing Factors of Protein Energy Malnutrition among Pregnant Women in a Nigerian Community. Online Journal of Health \& Allied Sciences, 3, 1.

[19] Undert, C.U., Sanchaisuriya, P., Sanchaisuriya, K., Schelp, F.P. and Schweigert, F.J. (2006) Nutritional Status of Pregnant Women in Northeast Thailand. Asia Pacific Journal of Clinical Nutrition, 15, 329-334.

[20] Folbre, N. (1986) Hearts and Spades: Paradigms of Household Economics. World Development, 14, $245-255$. http://dx.doi.org/10.1016/0305-750X(86)90056-2

[21] Leslie, J., Clemins, E. and Essama, S.B. (1997) Female Nutritional Status across Life-Span in Sub-Sahara Africa. I. Prevalence Patterns. Food and Nutrition Bulletin, 18, 20-43.

[22] Bhattacharya, S., Campbell, D.M., Liston, W.A. and Bhattacharya, S. (2007) Effect of Body Mass Index on Pregnancy Outcomes in Nulliparous Women Delivering Singleton Babies. BMC Public Health, 7, 168. http://dx.doi.org/10.1186/1471-2458-7-168

[23] United Nations Administrative Committee on Coordination/Sub-Committee on Nutrition (1992) Second Report on the World Nutrition Situation. Global and Regional Results, Geneva, 1.

[24] CSA (2010) The 2007 Population and Housing Census of Ethiopia: Statistical Report for Oromiya Region. CSA, Addis Ababa.

[25] Marano, D., de Gama, S.G., Pereira, A.P. and de Souza Jr., P.R. (2012) Adequacy of Weight Gain in Pregnant Women from Two Municipalities of Rio de Janeiro State (RJ), Brazil, 2008. Revista Brasileira de Ginecologia e Obstetrícia, 34, 386-393. http://dx.doi.org/10.1590/S0100-72032012000800008

[26] Andreto, L.M., de Souza, A.L., Figueiroa, J.N. and Cabral-Filho, J.E. (2006) Factors Associated with Excessive Gestational Weight Gain among Patients in Prenatal Care at a Public Hospital in Recife, Pernambuco, Brazil. Cadernos de Saúde Pública, 22, 2401-2409. http://dx.doi.org/10.1590/S0102-311X2006001100014 


\section{Abbreviations and Acronyms}

$\begin{array}{ll}\text { BMI } & \text { Low Body Mass Index } \\ \text { ANC } & \text { Antenatal Care } \\ \text { COR } & \text { Crude Odds Ratio } \\ \text { AOR } & \text { Adjusted Odds Ratio } \\ \text { Eth.birr } & \text { Ethiopian Birr } \\ \text { PEM } & \text { Protein Energy Malnutrition } \\ \text { IUGR } & \text { Intrauterine Growth Retardation } \\ \text { LMP } & \text { Last Menstrual Period } \\ \text { SPSS } & \text { Statistical package for Social Sciences } \\ \text { FDROE } & \text { Federal Democratic Republic of Ethiopia } \\ \text { MOPED } & \text { Ministry of Planning and Economic Development } \\ \text { WHO } & \text { World Health Organization } \\ \text { CSA } & \text { Central Statistics Authority }\end{array}$

